\title{
Common carotid artery stump pressure in the gerbil stroke model
}

\author{
RUDOLF LAAS
}

From the Department of Neuropathology, Eppendorf Hospitals, University of Hamburg, Fed Rep Germany

SUMMARY In 106 slightly anaesthetised adult mongolian gerbils one common carotid artery (CCA) was ligated and the blood pressure in the distal and in the proximal stump was monitored for 8 minutes. The mean distal CCA stump pressure of the 39 nonsurvivors was $15( \pm 6) \mathrm{mm} \mathrm{Hg}$, that of the 25 survivors with retinocerebral infarcts was $25( \pm 6) \mathrm{mm} \mathrm{Hg}$, and that of the 42 intact survivors was $31( \pm 7) \mathrm{mm} \mathrm{Hg}$. The corresponding mean arterial blood pressures (MABP), as measured in the proximal CCA stump, were $81( \pm 12) \mathrm{mm} \mathrm{Hg}, 84( \pm 13) \mathrm{mm} \mathrm{Hg}$, and $87( \pm 11)$ $\mathrm{mm} \mathrm{Hg}$, respectively. There were no differences between the samples concerning sex, body weight, rectal temperature, arterial blood gases, arterial $\mathrm{pH}$, and haematocrit. Measurements in a second series of 10 awake gerbils showed that the mean values of MABP, heart rate, and respiratory rate of the nonsurvivors were less than those of the survivors during 90 minutes after CCA ligation. It is inferred that in the mongolian gerbil the lower threshold of the arterial blood pressure for the development of brain infarcts ranges within 22 and $25 \mathrm{~mm} \mathrm{Hg}$, that is, within the values found in monkeys and cats. The longlasting depression of respiration and circulation in the nonsurvivors is considered to be related to the phenomenon of diaschisis.

As revealed by measurements in cats ${ }^{1}$ and monkeys $^{23}$ the threshold value of the arterial blood pressure for the development of brain infarcts appears to be consistent and clear-cut. From experiments on rats we gained some evidence that this in part may be due to collapse of the leptomeningeal veins which is considered to induce a steep increase of cerebrovascular resistance. ${ }^{4}$ In order further to substantiate this hypothesis, we determined the arterial blood pressure threshold value in rodents.

We chose the mongolian gerbil as the experimental animal, since this small rodent is inexpensive and offers some experimental advantages. Depending on the size of the posterior communicating artery and its contribution to the anterior circulation, the gerbils exhibit a greater or lesser susceptibility to brain infarction after ligation of one common carotid artery. ${ }^{56}$ From this we inferred that in the mon-

Address for reprint requests: Rudolf Laas, MD, Department of Neuropathology, Eppendorf Hospitals, University of Hamburg, Martinistrasse 52, 2000 Hamburg 20, Fed Rep Germany.

Received 7 July 1983 and in revised form 6 October 1983. Accepted 28 October 1983 golian gerbil the threshold value in question could be determined simply by measuring the arterial blood pressure distal to the common carotid artery (CCA) ligation and by relating this value to vital and/or histological outcome. Thus, the known risk of artificial reduction of systemic arterial blood pressure was avoided. ${ }^{3}$

In order to minimise stress, which is likely to worsen outcome, the measuring period was limited to a few minutes. We then attempted to gain insight into the course of systemic circulation and respiration in a second series.

\section{Material and methods}

Series I

One hundred and six adult mongolian gerbils ( 53 males, 53 females) had free access to standard chow and tap water.

The animals were anaesthetised with diethylether. The left common carotid artery (CCA) was ligated after midline incision of the neck. Catheters were inserted into the distal and proximal stump and connected to pressure transducers (P50, Statham, USA). The average duration of the procedure was 10 minutes. Modest anticoagulation was effected by the injection of heparin, so that no uncontroll- 
able wound bleeding occurred.

Distal and proximal blood pressures were monitored for 8 minutes. Respiratory rate was checked periodically. The transducers were then disconnected and a volume of 200 $\mu l$ of arterial blood was withdrawn through the proximal catheter for the determination of arterial pO2, pCO2, $\mathrm{pH}$, and haematocrit (IL Boskamp, FRG). The catheters were removed and the neck wound was closed with tissue adhesive (Histoacryl, Braun Melsungen, FRG). Immediately thereafter, the animals were placed into single cages, and their behaviour was registered for 5 hours by videotape recording (National, Japan). At intervals of 10 minutes the number of animals showing contra- or ipsiversive rotations and/or attacks or being in coma, was counted. Rotations are circling movements of moderate velocity around the vertical axis of the body the outer limbs being splayed. The term "attack" refers to seizure-like running and rolling movements. Rolling fits consist of violent corkscrew-like movements around the longitudinal axis of the body.

Brains and eyes of the dead animals were immersionfixed in $10 \%$ formalin containing $1 \%$ acetic acid. Ten days after CCA ligation the surviving animals were perfusionfixed through the ascending aorta with the same solution. After four hours of fixation the brains and eyes were dissected from the skull and embedded in paraffin and plastic polymer (Paraplast, Lancer, Ireland).

The brains were cut in two planes: one through the anterior commissure and the second through the largest extent of the thalamus. Sections $8 \mu \mathrm{m}$ thick were stained with cresyl violet and by the van Gieson technique.

\section{Series II}

In 10 animals (five males, five females), held as described above, additionally the mean arterial blood pressure (MABP) was monitored for 90 minutes after CCA ligation in the awake state.

The animals were anaesthetised with diethylether. The left CCA was ligated, and small catheters were inserted into the distal and proximal carotidal stumps and the distal one was connected to a pressure transducer as described for series I. The proximal catheter was connected to a soft tube, which was placed subcutaneously to the nape. A cannula with a oneway-stopcock was attached to the free end of the catheter and affixed to the skin with adhesive plaster and tissue glue (Histoacryl, Braun Melsungen, FRG). A small pressure transducer (P50, Statham, USA) was plugged directly into the stopcock. Its wires were led to amplifiers through a slip ring assembly (BRS, USA). Anticoagulation was effected as described for series I.

Arterial pressures distal and proximal to the CCA ligation were monitored for 8 minutes. Thereafter, the distal catheter was withdrawn, the neck wound was closed by tissue adhesive and the animal was placed into a perspex cylinder whose inner diameter was $50 \mathrm{~cm}$.

Throughout the observation period, the behaviour of the animals was monitored by videotape recording and the respiratory rate was registered periodically. At the end of the observation period the animals were anaesthetised with diethylether, the transducers were disconnected, and 200 $\mu \mathrm{l}$ of arterial blood was withdrawn for measurement of pO2, pCO2, pH, and haematocrit (IL Boskamp, FRG). Thereafter, the catheter was ligated at its distal end, can- nula and stopcock were removed, and the neck wound was closed by tissue adhesive.

The brains and eyes of the dead and surviving animals, were fixed and prepared for histological evaluation as described for series I.

\section{Results}

\section{SERIES I}

Lethality

After CCA ligation, 39 animals (21 males, 18 females) of 106 animals $(=37 \%)$ died after 80 minutes to 3 days (mean survival time: 25 hours, SD =9).

\section{Histological findings}

All animals which died after CCA ligation showed massive swelling of the ipsilateral hemisphere, softening of the tissue and midline herniations.

Nineteen surviving animals (eight males, 11 females) developed brain lesions with the histological pattern shown in table 1 . Nine of these 19 animals (neuronal necrosis two, total necrosis seven) also had total necrosis of the ipsilateral retina. In six surviving animals there was retinal necrosis without brain lesions. Retinal necrosis was regularly accompanied by shrinkage of the eye.

\section{Pathophysiological findings}

Table 2 presents the means of all variables monitored. Body weight and rectal temperature were registered before the animals were anaesthetised.

Mean arterial blood pressure (MABP) and mean distal common carotid artery stump pressure were computed from 15 values which were selected from the experimental records at intervals of 30 seconds. In the same animal, only very small variations of these values occurred. From these individual means the sample means were determined. The individual means are given in fig 1 .

The values of the mean distal common carotid artery stump pressure in the three samples permutationally differed from each other highly significantly (Student's $t$ test, $\mathrm{p}<0.001)$. The value of the MABP of the non-survivors was lower $(p<0.05$, Student's $t$ test) than that of the intact survivors. For none of the remaining variables could significant differences between the three samples be computed.

Table 1 Regional distribution of brain lesions in 19 surviving animals

\begin{tabular}{lccll}
\hline & $\begin{array}{l}\text { Corpus } \\
\text { striatum }\end{array}$ & $\begin{array}{l}\text { Hippo- } \\
\text { campus }\end{array}$ & Thalamus & $\begin{array}{l}\text { Cerebral } \\
\text { cortex }\end{array}$ \\
\hline Neuronal necrosis & 7 & 12 & 3 & 1 \\
Total necrosis & 5 & 5 & 5 & 5 \\
Sum & 12 & 17 & 8 & 6 \\
\hline
\end{tabular}


Table 2 Comparison of the physiological variables monitored a few minutes after CCA ligation (mean, standard deviation). MABP: mean arterial blood pressure; DCCASP: distal common carotid artery blood pressure.

\begin{tabular}{|c|c|c|c|}
\hline & $\begin{array}{l}\text { Intact } \\
\text { survivors } \\
n=42\end{array}$ & $\begin{array}{l}\text { Survivors } \\
\text { with infarcts } \\
n=25\end{array}$ & $\begin{array}{l}\text { Non- } \\
\text { survivors } \\
n=39\end{array}$ \\
\hline 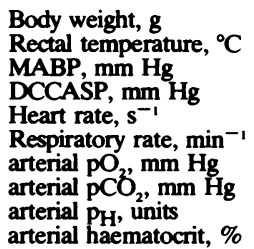 & $\begin{array}{l}69 \cdot 3(10) \\
38 \cdot 2(0.7) \\
87(11)^{*} \\
31(7) \dagger \\
5 \cdot 5(0 \cdot 8) \\
78(16) \\
110(18) \\
37(7) \\
7 \cdot 326(0.078) \\
43(4)\end{array}$ & $\begin{array}{l}67 \cdot 6(7) \\
38 \cdot 1(0 \cdot 6) \\
84(13) \\
25(6) \dagger \\
5 \cdot 3(0 \cdot 7) \\
71(13) \\
114(17) \\
33(8) \\
7 \cdot 321(0 \cdot 090) \\
42(3)\end{array}$ & $\begin{array}{l}66 \cdot 0(12) \\
38 \cdot 1(0 \cdot 6) \\
81(12) \\
15(6) \\
5 \cdot 3(0 \cdot 8) \\
74(11) \\
111(15) \\
33(7) \\
7 \cdot 307(0 \cdot 082) \\
42(2)\end{array}$ \\
\hline
\end{tabular}

( ${ }^{*} p<0.05 ; \dagger p<0.0001$; Student's $t$ test; ${ }^{*} p$ refers to the difference between the means of the intact survivors and the nonsurvivors)

The relationship between the distal common carotid artery stump pressure and the MABP in the individual animals is given in fig 1 . In order to illustrate the differences between the three groups regression lines were established.

Whereas signs were observed in all nonsurvivors during the whole observation period of five hours after the CCA ligation, they occurred only during the first hour after CCA ligation in 33 of the 42 intact survivors and in 12 of the 25 survivors with retinocerebral infarcts.

Whereas the curve of the intact survivors and that of the survivors with retinocerebral infarctions are very similar to each other, both differ highly significantly from that of the nonsurvivors (Chisquare). In the latter group animals with ipsiversive rotations and/or attacks predominate considerably. However, from the second to the third hour onwards the number of contraversively rotating animals increased gradually. The four animals which died during the observation period showed contraversive rotations and/or attacks before their death.

\section{SERIES II}

Lethality, histological findings

Five animals (two males, three females) died within 7 to 72 hours after CCA ligation. These animals showed massive swelling of the ipsilateral hemisphere with tissue softening and midline herniations. Two of the survivors had retinal and cerebral lesions.

\section{Pathophysiological findings}

The means of the distal common carotid artery stump pressure of the survivors and nonsurvivors were $27.8 \mathrm{~mm} \mathrm{Hg}(\mathrm{SD}=4.3)$ and $15.2 \mathrm{~mm} \mathrm{Hg}$ (SD $=3 \cdot 1)$, respectively $(\mathrm{p}<0.0001$, Student's $t$ test). The means of the corresponding MABP were 84.0 $\mathrm{mm} \mathrm{Hg}(\mathrm{SD}=4 \cdot 7)$ and $81.2 \mathrm{~mm} \mathrm{Hg}(\mathrm{SD}=3 \cdot 7)$.

There was no significant difference of MABP, heart rate, and respiratory rate between survivors and nonsurvivors during the first 10 minutes after CCA ligation (fig 3). The former two variables were at the level found in series $I$, the respiratory rate, however, was considerably higher. The animals awoke from anaesthesia at about 30 minutes after CCA ligation.

From the 30th minute onwards all values increased gradually. The steepness of this increase was significantly greater in the survivors than in the nonsurvivors. According to fig 3 these differences became significant for the three variables monitored

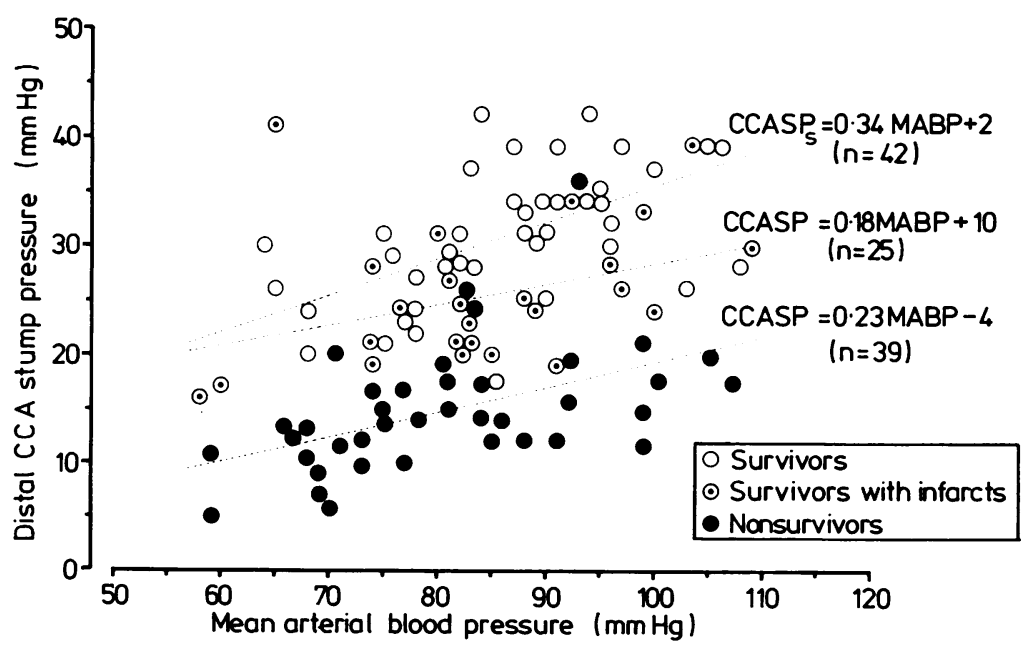

Fig 1 Mean arterial blood pressure (MABP) and corresponding distal common carotid artery stump pressure (DCCASP) of intact survivors, survivors with infarcts, and nonsurvivors. The regression lines were computed from the mean values obtained in the individual animals. 

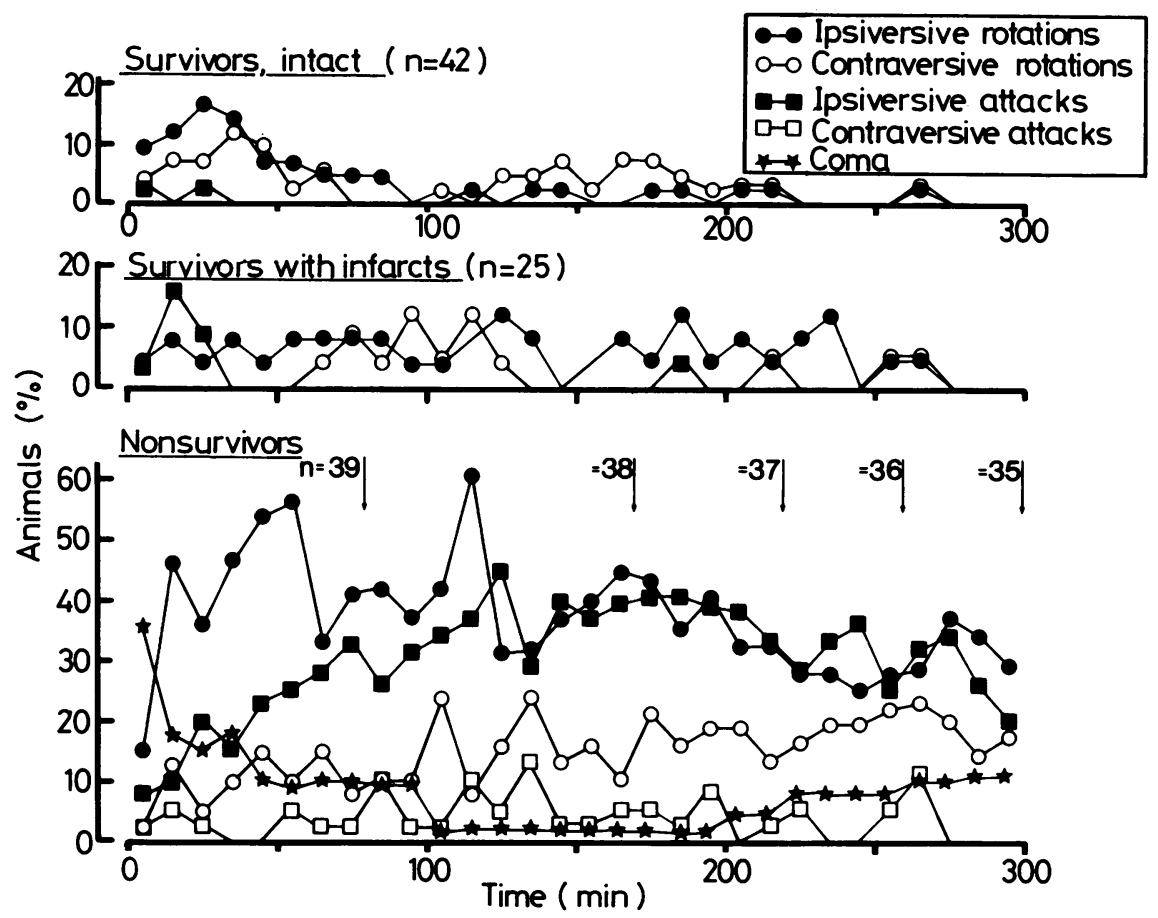

Fig 2 Changes in the percentage of gerbils displaying ipsi- or contraversive rotational behaviour following ligation of one common carotid artery. The arrows mark time points at which animals died; the reduced sample sizes are given by the numbers beside the arrows. During the 10 minute intervals the symptomats of animals were counted only once, that is with their predominating sign.

from the 70th minute after CCA ligation onwards (Student's $t$ test).

As shown in table 3 there were no differences in the blood gases, $\mathrm{pH}$, and haematocrit between the survivors and the nonsurvivors at the end of the observation period.

During the observation period of 90 minutes four of the nonsurvivors showed ipsiversive rotations and one of them displayed predominantly running and rolling attacks (fig 2). These signs took a course similar to that established for the nonsurvivors of series I. The survivors exhibited rotational behaviour only during the first $\mathbf{3 0}$ minutes. Thereafter they behaved quite normally. Seizures did not occur.

\section{Discussion}

The data demonstrate that in the mongolian gerbil the value of the distal common carotid artery stump pressure allows one to predict the outcome from permanent common carotid artery ligation reliably. Body weight, arterial blood gases, $\mathrm{pH}$, and haematocrit are shown to be related neither to stump pressure nor to outcome. Only the mean arterial blood pressure (MABP) tended to decline in parallel with the distal common carotid artery stump pressure.

It appears unlikely that the measuring procedure per se has worsened outcome considerably. The lethality rate of $37 \%$ is within the range of about 25 to $65 \%$ found by others in gerbils with mere unilateral CCA ligation. ${ }^{6-11}$ This holds too for the incidence and for the pattern of the regional infarcts of the survivors. ${ }^{112}$ In the small sample of series II the lethality rate was only slightly higher than that of series $\mathrm{I}$.

Furthermore, the values of MABP, arterial $\mathrm{pCO} 2, \mathrm{pH}$, and haematocrit, measured in the anaesthetised gerbils, approximately agree with data presented by others. ${ }^{13-16}$ The value of the arterial pO2 of $110 \mathrm{~mm} \mathrm{Hg}$ equals measurements in awake gerbils with bilateral CCA ligations ${ }^{15}$ but is in excess of the value of $90 \mathrm{~mm} \mathrm{Hg}$ measured in anaesthetised ${ }^{13}$ and in restrained awake gerbils ${ }^{17}$ with unilateral CCA ligation. The very high arterial pO2 and low pCO2 measured in series II at the end of the observation period probably are due to the diethyl-ether 

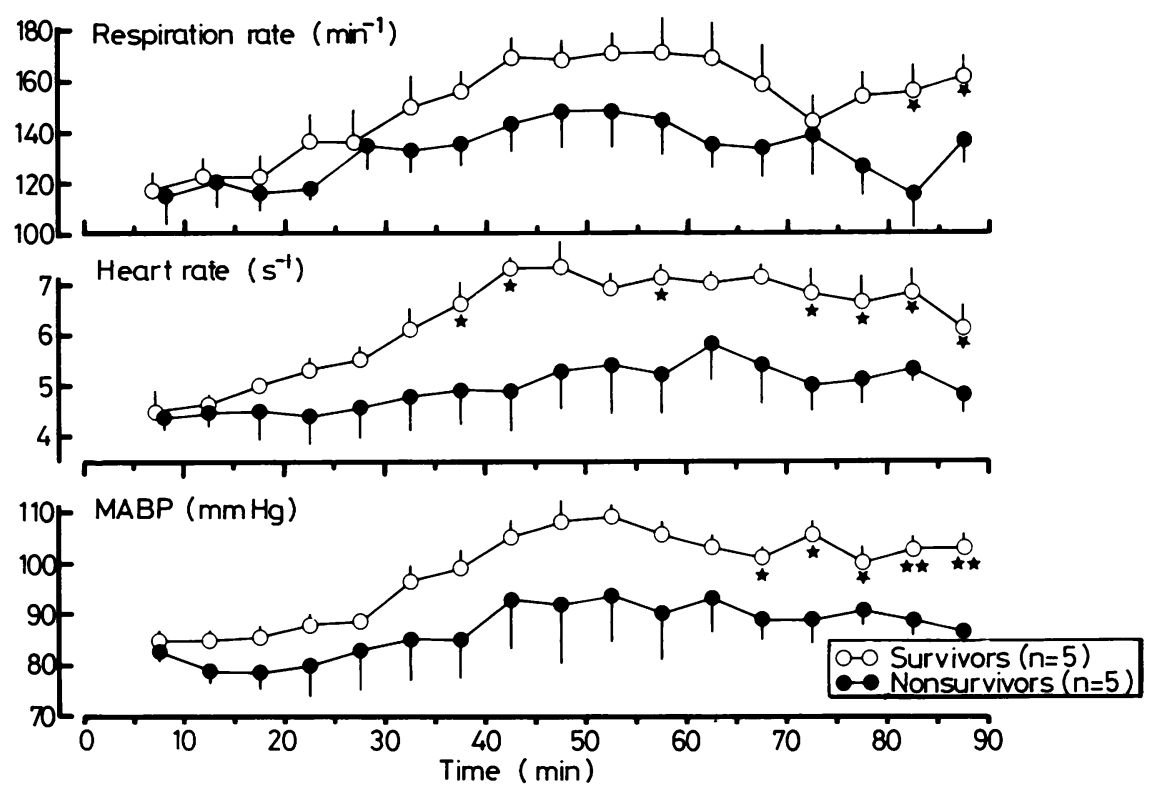

Fig 3 Changes in respiratory rate, heart rate, and mean arterial blood pressure (MABP) following ligation of one common carotid artery in 5 survivors and 5 nonsurvivors (Mean, SEM); $\star p<0.05 ; \star \star p<0.01$ (Student's t test).

induced hyperventilation.

The MABP of the survivors of series II increased during the first 50 minutes after CCA ligation to a level of about $100 \mathrm{~mm} \mathrm{Hg}$, whereas that of the nonsurvivors remained at about $90 \mathrm{~mm} \mathrm{Hg}$ (fig 3, table 3 ). Since the survivors behaved quite normally when completely awoken from anaesthesia, it appears that the quite stable pressure level of $100 \mathrm{~mm} \mathrm{Hg}$ reached at the end of the observation period represents the normal MABP level of the awake mongolian gerbil. Because of the pressure loss at the ipsilateral carotid bifurcation, there may be a small baroreceptor-mediated pressure increase as compared with gerbils with intact carotid arteries. ${ }^{14} 18$

Table 3 Comparison of the physiological variables registered at the end of the observation period of 90 minutes (mean, SD).

\begin{tabular}{|c|c|c|}
\hline & $\begin{array}{l}\text { Survivors } \\
n=5\end{array}$ & $\begin{array}{l}\text { Nonsurvivors } \\
n=5\end{array}$ \\
\hline $\begin{array}{l}\text { MABP, mm } \mathrm{Hg}^{-} \\
\text {Heart rate, } \mathrm{s}^{-1} \\
\text { Respiratory rate, min }{ }^{-1} \\
\text { arterial pO }, \mathrm{mm} \mathrm{Hg}^{-1} \\
\text { arterial pCO, } \mathrm{mm} \mathrm{Hg}_{2} \\
\text { arterial } \mathrm{p}_{\mathrm{H}}, \text { units } \\
\text { arterial haematocrit, \% }\end{array}$ & $\begin{array}{c}103(6) \dagger \\
6 \cdot 1(0.9) \\
152(32) \\
127(19) \mathrm{ns} \\
27(2) \mathrm{ns} \\
7.416 \\
(0.028) \\
44.9(2) \mathrm{ns}\end{array}$ & $\begin{array}{c}87(7) \\
4 \cdot 8(1 \cdot 2) \\
137(18) \\
129(14) \\
25(6) \\
7 \cdot 381 \\
(0 \cdot 037) \\
45 \cdot 3(1)\end{array}$ \\
\hline
\end{tabular}

( ${ }^{*} \mathrm{p}<0.05 ; \mathrm{\dagger p}<0.01 ;$ Student's $t$ test)
The MABP and the heart rate of the survivors equals that registered in rats which had undergone a similar measuring procedure. ${ }^{19}$

Taken together, it appears justifiable to deduce from our data threshold values representative for this mongolian gerbil stroke model.

Until now threshold values of the arterial blood pressure for the development of regional brain infarcts have been established only for monkeys ${ }^{23}$ and cats ${ }^{120}$ which were made hypotensive by bleeding and/or application of ganglion blocking agents with the blood gases and $\mathrm{pH}$ being thoroughly controlled.

The lower threshold, that is, that with the smallest time need of about 30 minutes, was found to be 22 to $25 \mathrm{~mm} \mathrm{Hg} .{ }^{13}$ Since the time need of this threshold value is minimum, it is likely to correspond to the threshold value for maximum lesions with the duration of carotid occlusions being unlimited. Indeed, this threshold value is quite similar to the lower threshold value found in this study.

Assuming that in our animals the thresholds of the distal common carotid artery stump pressure for lethal and for survived infarcts, lie between the mean stump pressures of the nonsurvivors, the survivors with infarcts, and the intact survivors, respectively, they can be estimated according to table 1 and fig 1 to be 20 and $28 \mathrm{~mm} \mathrm{Hg}$, respectively.

However, since the MABP of the nonsurvivors 
and that of the survivors increased by about 15 and $25 \mathrm{~mm} \mathrm{Hg}$, respectively, during the first 50 minutes after CCA ligation, the thresholds may be somewhat higher, that is, 22 and $30 \mathrm{~mm} \mathrm{Hg}$. This extrapolation seems justifiable since according to fig 1 there is an approximately linear relationship between the distal common carotid artery stump pressure and the proximal one. Probably these corrected values still underestimate the true threshold values, since primary collaterals may further increase the distal stump pressure during the first hour after CCA ligation depending on the magnitude of the pressure reduction. ${ }^{21}$

The course of the respiratory and especially of the circulatory variables monitored after CCA ligation in the awake gerbils of series II has proved to be of decisive importance for the threshold determination. Comparable data for the mongolian gerbil are not yet available. In cats developing large infarcts after occlusion of one medial cerebral artery and showing only moderate consecutive increase of intracranial pressure severe systemic hypotension was observed. ${ }^{22}$ In rabbits global ischaemia of more than 7.5 minutes duration has been shown to induce an initial steep increase of the MABP which was regularly followed by a severe MABP drop. ${ }^{23}$

In accordance with these investigations we assume that also in our animals this circulatory depression is caused by a central mechanism. As shown in table 3 it cannot be explained by changes in arterial blood gases, $\mathrm{pH}$, and haematocrit. Possibly this global functional depression is related to what is called diaschisis. This tefm refers to the finding that regional cerebral ischaemia may induce functional and circulatory depression in remote brain areas..$^{24}{ }^{25} \mathrm{In}$ the mongolian gerbil stroke model transhemispheric diaschisis has been proved to occur in parallel with regional cerebral blood flow, ${ }^{13} 17$ EEG, ${ }^{11}$ and biochemical variables. ${ }^{96}$ Recently transtentorial depression of regional cerebral blood flow also has been shown to appear in this model. ${ }^{16}$ It is of special interest that this transtentorial diaschisis occurred only in those animals in whom cerebral blood flow had fallen below the lower threshold for cerebral infarct development. ${ }^{132728}$ It should be mentioned that in patients with acute stroke, diaschisis was accompanied by a relative systemic hypotension. ${ }^{25}$

In accordance with the observations of others $^{69111726}$ we saw in addition to the circling movements adversive attacks. However, since the time courses of both phenomena were fairly similar to each other (fig 2), we regarded them as equivalent neurological signs - using for both jointly the term rotational behaviour.

It is generally accepted that in small rodents the functional dominance of one cerebral hemisphere induces contraversive rotating movements. ${ }^{29}$ Thus, the preponderance of ipsiversive rotational behaviour in the nonsurvivors, which has been also observed by others, ${ }^{12} 30$ would correspond well with depletion of catechol amines in the ipsilateral basal ganglia. ${ }^{31}{ }^{32}$ However, it should be stressed that this inference does not accord with all pertinent data. ${ }^{33}$

In the survivors virtually no rotational behaviour was observed (fig 2). This is in contrast to what we have seen in rats developing unilateral brain lesions due to ligation of one CCA and subsequent exposure to carbon monoxide. ${ }^{19}$ Since in the Mongolian gerbil stroke model general hypoxaemia/anaemia plays no role, this difference accords with the assumption that in these small rodents the manifestation of asymmetrical neurological signs requires unbalanced functional impairment of both hemispheres. ${ }^{17}$

The increase of the rate of contraversively rotating nonsurvivors from the second to the third hour of the observation period onwards probably reflects - in accordance with data of others ${ }^{9} 111334$ the development of lethal brain oedema. In a previous study we saw the same phenomenon in rats with lethal unilateral brain lesions approximately coincide with breakdown of the blood-brain barrier. ${ }^{19}$ Thus, in the nonsurvivors contraversive rotational behaviour probably indicates irreversibility of the brain lesion.

In conclusion, our data substantiate the suggestion that there is a well defined lower threshold of the arterial blood pressure for the development of brain infarcts in gerbils of about 22 to $25 \mathrm{~mm} \mathrm{Hg}$. There is some evidence that this threshold does not depend on species. It may be mentioned that in humans with atherosclerosis unilateral carotid occlusion for carotid endarterectomy has been considered to be without hazard for brain perfusion when the distal common carotid artery stump pressure remains above the level of $25 \mathrm{~mm} \mathrm{Hg}{ }^{35}$

The predictive value of the distal common carotid artery stump pressure was shown to be superior to that of neurological signs, which (and this is generally accepted) allow a prediction only of lethal brain lesions and not nonlethal regional brain infarcts. Moreover, the development of lethal brain lesions was shown to be accompanied by a circulatory and respiratory depression which is thought to be related to the phenomenon of diaschisis.

The author is indebted to Mrs A Junge for skilful technical assistance.

\footnotetext{
References

' Graham DI, Fitch W, MacKenzie ET, Harper AM. Effects of hemorrhagic hypotension on the cerebral circulation. Stroke 1979;10:724-7.
} 
${ }^{2}$ Brierley JB, Brown AW, Excell BJ, Meldrum BS. Brain damage in the rhesus monkey resulting from profound arterial hypotension. I. Its nature, distribution and general physiological correlates. Brain Res 1969;13:69-100.

${ }^{3}$ Selkoe DJ, Myers RE. Neurological and cardiovascular effects of hypotension in the monkey. Stroke 1979; 10:147-57.

${ }^{4}$ Laas R, Igloffstein J. Cerebral infarction due to carotid occlusion and carbon monoxide exposure. III. Influence of neck vein occlusion. J Neurol Neurosurg Psychiatry 1983;46:774-9.

${ }^{5}$ Levy DE, Brierley JB. Communications between vertebro-basilar and carotid arterial circulations in the gerbil. Exp Neurol 1974;45:503-8.

- Harrison MJG, Brownhill D, Lewis PD, Ross Russell RW. Cerebral oedema following carotid artery ligation in the gerbil. Arch Neurol 1973;28:389-91.

7 Payan HM, Conard JR. Carotid ligation in gerbils. Stroke 1977;8:194-6.

${ }^{8}$ McGraw CP. Experimental cerebral infarction effects of pentobarbital in mongolian gerbils. Arch Neurol 1977;34:334-6.

9 Welch KMA, Chabi E, Buckingham J, Bergin B, Achar VS, Meyer JS. Catecholamine and 5-Hydroxytryptamine levels in ischemic brain. Stroke 1977;8:341-6.

${ }^{10}$ Butterfield JD, McGraw CP. Effect of DPPD (Diphenyl-para-phenylenediamine) on stroke and cerebral edema in gerbils. Stroke 1978;9:480-3.

"Yanagihara T. Experimental stroke in gerbils: correlation of clinical, pathological and electroencephalographic findings and protein synthesis. Stroke 1978;9:155-9.

${ }^{12}$ Levy DE, Brierley JB, Plum F. Ischaemic brain damage in the gerbil in the absence of "no-reflow". J Neurol Neurosurg Psychiatry 1975;38:1197-205.

${ }^{13}$ Crockard A, Iannotti F, Hunstock AT, Smith RD, Harris RJ, Symon L. Cerebral blood flow and edema following carotid occlusion in the gerbil. Stroke 1980;11:494-8.

${ }^{14}$ Pollock S, Tsitsopoulos P, Harrison MJG. The effect of haematocrit on cerebral perfusion and clinical status following carotid occlusion in the gerbil. Stroke 1982;13: $167-70$.

is Ito U, Ohno K, Yamaguchi T, Tomita H, Inaba Y, Kashima M. Transient appearance of "no-reflow" phenomenon in mongolian gerbils. Stroke 1980;11:517-21.

${ }^{16}$ Naritomi H. Transtentorial diaschisis: reduction of cerebellar blood flow caused by supratentorial local cerebral ischemia in the gerbil. Stroke 1983;14:213-8.

${ }^{17}$ Levy DE, Van Uitert RL, Pike CL. Delayed postischemic hypoperfusion: a potentially damaging consequence of stroke. Neurology (Minneap) 1979;29: 1245-52.

${ }^{18}$ Iriuchijima J, Koike H. Carotid flow, intrasinusal pressure, and collateral flow during carotid occlusion. Am J Physiol 1970;218:876-9.

${ }^{19}$ Laas R, Igloffstein J, Meyerhoff S. Cerebral infarction due to carotid occlusion and carbon monoxide exposure. I. Pathophysiological and neuropathological investigations. J Neurol Neurosurg Psychiatry 1983;46:756-67.

${ }^{20}$ Gregory PC, McGeorge AP, Fitch W, Graham DI, MacKenzie ET, Harper AM. Effects of hemorrhagic hypotension on the cerebral circulation. II. Electrocortical function. Stroke 1979;10:719-23.

${ }^{21}$ Meyer JS, Denny-Brown D. The cerebral collateral circulation. I. Factors influencing collateral blood flow. Neurology (Minneap) 1957;7:447-58.

${ }^{22}$ Hayakawa T, Waltz AG. Intracranial pressure, blood pressure, and pulse rate after occlusion of a middle cerebral artery in cats. J Neurosurg 1975;43:399-407.

${ }^{23}$ Kowada M, Ames A III, Majno G, Wright RL. Cerebral ischemia. I. An improved experimental method for study: cardiovascular effects and demonstration of an early vascular lesion in the rabbit. $J$ Neurosurg 1968;28:150-7.

${ }^{24}$ Meyer JS, Shinohara Y, Kanda T, Fukuuchi Y, Ericsson AD, Kok NK. Diaschisis resulting from acute unilateral cerebral infarction. Arch Neurol 1970;23:241-7.

${ }^{25}$ Slater R, Reivich M, Goldberg H, Banka R, Greenberg J. Diaschisis with cerebral infarction. Stroke 1977;8:684-90.

${ }^{26}$ Harrison MJG, Ellam LD. Role of $5 \mathrm{HT}$ in the morbidity of cerebral infarction-a study in the gerbil stroke model. J Neurol Neurosurg Psychiatry 1981;44:1403.

${ }^{27}$ Jones TH, Morawetz RB, Crowell RM, Marcoux FW, FitzGibbon SJ, DeGirolami U, Ojemann RG. Thresholds of focal cerebral ischemia in awake monkeys. J Neurosurg 1981;54:773-82.

${ }^{28}$ Marcoux FW, Morawetz RB, Crowell RM, DeGirolami U, Halsey JH. Differential regional vulnerability in transient focal cerebral ischemia. Stroke 1982;13:339-46.

${ }^{29}$ Ungerstedt U. Striatal dopamine release after amphetamine or nerve degeneration revealed by rotational behaviour. Acta Physiol Scand 1971; Suppl 367:49-68.

${ }^{30}$ Nakai K, Welch KMA, Meyer JS. Critical cerebral blood flow for production of hemiparesis after unilateral carotid occlusion in the gerbil. J Neurol Neurosurg Psychiatry 1977;40:595-9.

${ }^{31}$ Zervas NT, Hori H, Negora M, Wurtman RJ, Larin F, Lavyne $M$. Reduction in brain dopamine following experimental cerebral ischemia. Nature 1974; 247:283-4.

${ }^{32}$ Lavyne M, Moskowitz M, Zervas N, Wurtman R. Rotational behaviour in gerbils following unilateral common carotid artery ligation. J Neural Transm 1975;36:83-89.

${ }^{33}$ Harrison MJG, Marsden CD, Jenner P. Effect of experimental ischemia on neurotransmitter amines in the gerbil brain. Stroke 1979;10:165-8.

${ }^{34}$ Yanagihara T. Cerebral ischemia in gerbils: differential vulnerability of protein, RNA, and lipid syntheses. Stroke 1976;7:260-3.

${ }^{35}$ Hunter GC, Sieffert G, Malone JM, Moore WS. The accuracy of carotid back pressure as an index for shunt requirementrs. A reappraisal. Stroke 1982;13:31926. 